\title{
High adiposity: risk factor for dementia and Alzheimer's disease?
}

\author{
Deborah R Gustafson ${ }^{1,2^{*}}$ and José A Luchsinger ${ }^{3}$
}

\begin{abstract}
Higher levels of total and central adiposity, measured as higher body mass index (BMI) (in kilograms per square meter), waist circumference, or waist-to-hip ratio, have been associated with late-onset Alzheimer's disease (AD). However, some epidemiologic studies do not support this association, and potential underlying biological mechanisms that provide biological plausibility are not clear in terms of providing direct links to adipose tissue. Studies linking adiposity to AD have considered adiposity measures from mid-life and late-life. Given an evolving background trajectory of BMI that exists over the life course and the influence of dementia processes on BMI, results have been conflicting depending on when BMI is measured in relationship to clinical AD onset. This has made interpretation of the BMI-AD literature difficult. This debate will briefly review the epidemiologic evidence for and against an association between higher adiposity and AD, issues of timing of the adiposity measure in relation to AD onset, potential biological mechanisms for observed associations, and explanations for conflicting evidence.
\end{abstract}

\section{Introduction}

In 2003, the association between higher adiposity, estimated higher body mass index (BMI) and late-onset Alzheimer's disease (AD) was published [1]. Whether higher adiposity, manifested as overweight and obesity, can cause AD remains controversial. The main reason for this controversy is that epidemiological studies show conflicting data on the association of adiposity and AD. Some studies show increased $\mathrm{AD}$ risk in relation to higher adiposity, some studies show lower risk, some studies show non-linear associations, and some studies show no association. This debate will briefly review the evidence for and against an association between higher adiposity and $\mathrm{AD}$.

\section{Evidence supporting an association between higher adiposity and Alzheimer's disease}

Some of the most compelling evidence comes from studies of mid-life risk factors. Higher adiposity at mid-life is associated with a higher risk for dementia or AD in epidemiologic studies [2-5], whether measured as BMI or

\footnotetext{
* Correspondence: Deborah.gustafson@downstate.edu

${ }^{1}$ Department of Neurology, Section for NeuroEpidemiology, State University of New York-Downstate Medical Center, 450 Clarkson Avenue, Box 1213, Brooklyn, NY 11203, USA

${ }^{2}$ Institute for Neuroscience and Physiology, Neuropsychiatric Epidemiology Unit, Sahlgrenska Academy at the University of Gothenburg, Wallinsgatan 6, 43141, Gothenburg, Sweden

Full list of author information is available at the end of the article
}

central obesity. Increased adiposity is an important mortality risk factor, and most studies showing an association between higher adiposity and dementia point to its being a survivorship phenomenon. It is observed among those who survive long enough to be at risk for late-onset dementia/AD, which usually means survivorship beyond 65 years of age. Most studies [1-3,6-9] show that a high $\mathrm{BMI}$ is a risk factor for dementia when measured at least a decade prior to a clinical dementia diagnosis. Fewer studies in late-life (for example, older than 65 years) show this association compared with those in mid-life $[1,10]$. Elevated adiposity in late-life is also associated with the alterations in brain structure and function that typically accompany cognitive deficits, dementia, and $\mathrm{AD}$. These alterations include decreased gray matter volumes, increased white matter lesions, and reduced white matter integrity. More specifically, abnormalities in brain regions such as the amygdala, hippocampus, and frontal cortex; decreased cortical thickness; axonal degradation; and decreased functional connectivity in the brain have been observed. Some of this literature has been reviewed [11].

There is biological evidence that elevated adiposity is an independent risk factor for dementia/AD. This comes primarily from the fact that adiposity is a risk factor for or on the causal pathway leading to hypertension, type 2 diabetes, and cardiovascular diseases, all of which have also been shown to increase risk for dementia [12]. It is 
plausible that elevated adiposity could increase the risk of dementia through cerebrovascular disease, decreasing the threshold for manifestation of AD pathology, or directly by affecting the accumulation of amyloid or neurodegenerative processes in the brain, the culprit of AD [12]. In addition, adipose tissue is metabolically active, secreting adipokines and sex hormones, whose actions on the brain we are still learning [13].

\section{Evidence against an association between elevated adiposity and Alzheimer's disease}

Some studies of mid-life adiposity, including a cohort study of Japanese-American men [14] and a cohort of Swedish women [15], have not found an association between elevated adiposity and dementia. Several studies report inverse $[5,16,17]$ or non-linear [18] associations between elevated adiposity and dementia. Although postulating that elevated adiposity could be beneficial for cognition seems implausible, the finding that leptin, which is elevated with elevated adiposity, is neuroprotective and associated with lower AD risk [19] could provide an explanation.

\section{Explanations for conflicting evidence}

Potential reasons that could explain the conflicting evidence include biases that affect the study of the association of adiposity and $\mathrm{AD}$, competing risks, reverse causality, and lifespan trajectories of adiposity. Elevated adiposity is a risk factor for increased mortality. Thus, persons with elevated adiposity may not survive to the age at which they would develop $\mathrm{AD}$ in some cohorts, explaining negative or inverse associations. Error in the measurement of adiposity may also be an issue [12]. In particular, BMI may not be a good measure of adiposity in old age, and at least two studies have shown no association of adiposity with $A D$ by using BMI but have demonstrated an association by using measures of central obesity $[10,20]$. However, a recent study compared measures of adiposity in relation to cognition and found the same inverse association across measures [21]. Competing risks are common in evaluating associations between high adiposity and disease since high adiposity is greatly correlated with other morbidities, such as hypertension. This makes it difficult to statistically dissociate the effect of high BMI from that associated with vascular phenotypes. In terms of reverse causality, it has been shown that weight loss may precede the diagnosis by decades [22]. Reverse causality seems plausible because $\mathrm{AD}$ is known to affect olfaction early and this could affect eating behavior. In addition, latent $\mathrm{AD}$ may be accompanied by metabolic changes that we do not yet understand. Studies allowing the description of life course trajectories (that is, those with lengthy, repeated follow-ups, and extending from mid- to late-life) show that the direction of the BMI-AD relationship changes direction during adult life. As such, both elevated adiposity in mid-life and lower BMI or body weight in late-life are associated with higher dementia/AD risk [15,20]. In addition, as shown in a Swedish cohort of women followed for over 37 years, there was a lesser increase in BMI from ages 38 to 70 years among the women who developed dementia compared with those who did not. Subsequently, after age 70, the BMI slope decreased similarly (no 'accelerated decline') in women with and those without dementia $[11,15]$. A lower BMI before and during dementia onset was also observed. This is in contrast to the Honolulu-Asia Aging Study, a study of Japanese-American men, in which baseline body weight was not related with dementia onset, but rate and degree of body weight decline were [14]. This latter observation is also evident in later-life studies such as the Religious Orders study [23] and using clinical data from the National Alzheimer Coordinating Center [24].

Many biological hypotheses have been brought forward with regard to this reverse epidemiological phenomenon and include the relative balance between vascular and neurodegenerative events from mid- to late-life; the action of endocrine adipose (in particular, leptin, a predominant adipose tissue hormone); changes in body composition with aging to include morphological changes in fat cells and the adipose tissue compartment, diminishing muscle mass, sarcopenia, and somatic frailty; and among women, especially, there is the role of reproductive aging and changes in the sex hormone milieu, a source of which is adipose tissue. Finally, observed trajectories of BMI, accompanied by the changes that are observed with $\mathrm{AD}$ and aging, point to a potential dysregulation of energy metabolism in development of AD neuropathology as well as clinical AD. This dysregulation may be driven, in part, by changes in body composition with aging, leading ultimately to sarcopenia and frailty in the periphery and cognitive frailty in the brain.

\section{Conclusions}

At the simplest level, there are not one, but several statements about this controversial literature on elevated adiposity and $\mathrm{AD}$. In mid-life, elevated adiposity can be considered a risk factor for dementia/AD. This relationship seems much more complicated in late-life. Declining body weight and BMI resulting in low BMI could be a marker of dementia/AD risk in late-life. Elevated adiposity in late-life could also be a risk factor when accompanied by cerebrovascular risk factors. However, elevated adiposity in late-life is also a marker of factors associated with survival and overall general health. Lastly, it is important to determine whether factors associated with adiposity, such as leptin, are neuroprotective. It is possible that the balance between detrimental and beneficial factors associated with adiposity determines cognitive outcomes, particularly in survivors to old age. This issue requires more research 
given the global epidemic of elevated adiposity, overweight and obesity, and the longer survival of the population.

\section{Abbreviations}

AD: Alzheimer's disease; BMI: Body mass index.

\section{Competing interests}

The authors declare that they have no competing interests.

\section{Acknowledgments}

DRG is supported by the EU 7th framework LipiDiDiet project (FP7/2007-2015) under grant agreement 211696; NIH/NIAID U01 318345; Swedish Research Council Diarienummer: 523-2005-8460; and the State University of New York Research Foundation. JAL is supported by National Institutes of Health grants P60 MD 000206, U01DK048404, PO1HD35897, R01AG37212, U01DK098246, and R01NR144430

\section{Author details}

${ }^{1}$ Department of Neurology, Section for NeuroEpidemiology, State University of New York-Downstate Medical Center, 450 Clarkson Avenue, Box 1213, Brooklyn, NY 11203, USA. ${ }^{2}$ Institute for Neuroscience and Physiology, Neuropsychiatric Epidemiology Unit, Sahlgrenska Academy at the University of Gothenburg, Wallinsgatan 6, 43141, Gothenburg, Sweden. ${ }^{3}$ Columbia University Medical Center, PH9 Center, room 210, 630 West $168^{\text {th }}$ Street, New York, NY 10032, USA

\section{Published: 18 Nov 2013}

\section{References}

1. Gustafson DR, Rothenberg E, Blennow K, Steen B, Skoog I: An 18-year follow up of overweight and risk for Alzheimer's disease. Arch Intern Med 2003, 163:1524-1528.

2. Whitmer RA, Gunderson EP, Barrett-Connor E, Quesenberry CP Jr, Yaffe K Obesity in middle age and future risk of dementia: a 27 year longitudinal population based study. BMJ 2005, 330:1360-1364.

3. Whitmer RA, Gunderson EP, Quesenberry CP Jr, Zhou J, Yaffe K: Body mass index in midlife and risk of Alzheimer disease and vascular dementia. Curr Alzheimer Res 2007, 4:103-109.

4. Whitmer RA, Gustafson DR, Barrett-Connor E, Haan MN, Gunderson EP, Yaffe K: Central obesity and increased risk of dementia more than three decades later. Neurology 2008, 71:1057-1064.

5. Fitzpatrick AL, Kuller LH, Lopez OL, Diehr P, O'Meara ES, Longstreth WT Jr, Luchsinger JA: Midlife and late-life obesity and the risk of dementia: cardiovascular health study. Arch Neurol 2009, 66:336-342.

6. Hayden KM, Zandi PP, Lyketsos CG, Khachaturian AS, Bastian LA, Charoonruk G, Tschanz JT, Norton MC, Pieper CF, Munger RG, Breitner JC, Welsh-Bohmer KA, Cache County Investigators: Vascular risk factors for incident Alzheimer disease and vascular dementia: the Cache County study. Alzheimer Dis Assoc Disord 2006, 20:93-100.

7. Kivipelto M, Ngandu T, Fratiglioni L, Viitanen M, Kareholt I, Winblad B, Helkala EL, Tuomilehto J, Soininen H, Nissinen A: Obesity and vascular risk factors at midlife and the risk of dementia and Alzheimer disease. Arch Neurol 2005, 62:1556-1560.

8. Rosengren A, Skoog I, Gustafson D, Wilhelmsen L: Body mass index, other cardiovascular risk factors, and hospitalization for dementia. Arch Intern Med 2005, 165:321-326.

9. Chiang CJ, Yip PK, Wu SC, Lu CS, Liou CW, Liu HC, Liu CK, Chu CH, Hwang CS, Sung SF, Hsu YD, Chen CC, Liu SI, Yan SH, Fong CS, Chang SF, You SL, Chen CJ: Midlife risk factors for subtypes of dementia: a nested case-control study in Taiwan. Am J Geriatr Psychiatry 2007, 15:762-771.

10. Luchsinger JA, Cheng D, Tang MX, Schupf N, Mayeux R: Central obesity in the elderly is related to late-onset Alzheimer disease. Alzheimer Dis Assoc Disord 2012, 26:101-105.

11. Gustafson DR: Adiposity and cognitive decline: underlying mechanisms. J Alzheimers Dis 2012, 30:S97-S112.

12. Luchsinger JA, Gustafson DR: Adiposity, type 2 diabetes, and Alzheimer's disease. J Alzheimers Dis 2009, 16:693-704.

13. Arnoldussen IA, Kiliaan AJ, Gustafson DR: Obesity and dementia: adipokines interact with the brain. Eur J Neuropsychopharmacology. in press.
14. Stewart $R$, Masaki $K$, Xue $Q-L$, Peila $R$, Petrovitch $H$, White $L R$, Launer LJ: A 32-year prospective study of change in body weight and incident dementia: the Honolulu-Asia Aging Study. Arch Neurol 2005, 62:55-60

15. Gustafson D, Bäckman K, Joas E, Waern M, Östling S, Guo X, Skoog I: A 37-year longitudinal follow-up of body mass index and dementia in women. J Alzheimers Dis 2012, 28:162-171.

16. Atti AR, Palmer K, Volpato S, Winblad B, De Ronchi D, Fratiglioni L: Late-life body mass index and dementia incidence: nine-year follow-up data from the Kungsholmen Project. J Am Geriatr Soc 2008, 56:111-116.

17. Nourhashémi F, Deschamps V, Larrieu S, Letenneur L, Dartigues JF, Barberger-Gateau P, PAQUID study: Personnes Agées Quid: body mass index and incidence of dementia: the PAQUID study. Neurology 2003 , 60:117-119.

18. Luchsinger JA, Patel B, Tang MX, Schupf N, Mayeux R: Measures of adiposity and dementia risk in elderly persons. Arch Neurol 2007, 64:392-398.

19. Lieb W, Beiser AS, Vasan RS, Tan ZS, Au R, Harris TB, Roubenoff R, Auerbach S, DeCarli C, Wolf PA, Seshadri S: Association of plasma leptin levels with incident Alzheimer disease and MRI measures of brain aging. JAMA 2009, 302:2565-2572.

20. Gustafson DR, Bäckman K, Waern M, Östling S, Guo X, Zandi PP, Mielke MM, Bengtsson C, Skoog I: Adiposity indicators and dementia over 32 years in Sweden. Neurology 2009, 73:1559-1566.

21. Luchsinger JA, Biggs ML, Kizer JR, Barzilay J, Fitzpatrick A, Newman A, Longstreth WT, Lopez O, Siscovick D, Kuller L: Adiposity and cognitive decline in the cardiovascular health study. Neuroepidemiology 2013, 40:274-281.

22. Knopman DS, Edland SD, Cha RH, Petersen RC, Rocca WA: Incident dementia in women is preceded by weight loss by at least a decade. Neurology 2007, 69:739-746.

23. Buchman AS, Wilson RS, Bienias JL, Shah RC, Evans DA, Bennett DA: Change in body mass index and risk of incident Alzheimer disease. Neurology 2005, 65:892-897.

24. Besser LM, Gill DP, Mosell SE, Brenowetz W, Moranus D, Kukull WA, Gustafson DR: Body mass index, weight change, and clinical progression in mild cognitive impairment and Alzheimer's disease. Alzheimer Dis Assoc Disord. in press.

10.1186/alzrt221

Cite this article as: Gustafson and Luchsinger: High adiposity: risk factor for dementia and Alzheimer's disease? Alzheimer's Research \& Therapy 2013, 5:57 